\title{
Cancer mortality among shoe manufacturing workers: an analysis of two cohorts
}

Hua Fu, Paul A Demers, Adele Seniori Costantini, Paul Winter, Didier Colin, Manolis Kogevinas, Paolo Boffetta

\begin{abstract}
Objectives-To examine the cancer risk of shoe manufacturing workers and evaluate whether the risk was associated with exposure to leather dust and solvents.

Method-Data from two historical cohort studies of shoe workers were expanded and analysed in parallel. A total of 4215 shoemakers from England contributing 103726 person-years at risk and 2008 shoemakers from Florence, Italy, contributing 54395 person-years at risk were included in the analysis. Exposure to leather dusts and solvents from glues was evaluated on the basis of job title information. Standardised mortality ratios (SMR) were calculated as ratios of observed deaths (Obs) over expected derived from national mortalities.
\end{abstract}

Results-Overall mortality was lower than expected in both cohorts (English cohort: Obs 3314, SMR 81, 95\% confidence interval (95\% CI) 78-84; Florence cohort: Obs 333, SMR 87, 95\% CI 78-97). An increased risk of nasal cancer was found (English cohort: Obs 12, SMR 741; Florence cohort: Obs 1, SMR 909). 10 of the 13 cases occurred among English workers employed in the manufacture of welted boots (SMR 926, 95\% CI 444-1703), a sector of the industry thought to have had the highest exposure to leather dust. Mortality from leukaemia was not increased in the English cohort (Obs 16, SMR 89), but was increased in the Florence cohort (Obs 8, SMR 214, 95\% CI 92-421); and the highest risk was found among shoe workers in Florence who were first exposed between 1950 and 1959 when exposure to benzene was substantial (Obs 3, SMR 536, 95\% CI 111-1566). Some evidence for an excess risk of stomach, bladder, and kidney cancer, as well as multiple myeloma and non-Hodgkin's lymphoma was also found in the Florence cohort only among workers employed in jobs with the highest exposure to solvents. Conclusions-These findings confirm the associations between exposure to leather dust and nasal cancer and between exposure to benzene and leukaemia in the shoe manufacturing industry and suggest that the risk of other cancers may be increased among workers exposed to solvents or glues.

(Occup Environ Med 1996;53:394-398)
Keywords: shoe workers, leather dust, benzene, solvents, malignant neoplasms, nasal cancer, leukaemia

In 1980, and again in 1987, the International Agency for Research on Cancer concluded that there is an excess risk of cancer among people employed in the boot and shoe manufacture and repair industry. ${ }^{12}$ The strongest evidence cited was for excess risks of nasal cancer and leukaemia. Excesses of other cancers, such as bladder, kidney, stomach, rectum, and lung have been found among shoe and leather workers but have been less consistently reported and have not been linked with particular exposures within the industry. ${ }^{3-9}$ Few studies were large enough and had adequate exposure data to examine the risk of cancer within subgroups of workers with different exposures.

We have conducted a parallel analysis of data from two cohorts of shoe manufacturing workers. Results from both cohorts have been previously reported, ${ }^{67}$ but for a shorter period of follow up. The goal of this study was to gain further knowledge on the risk of cancer among workers in this industry and to evaluate whether the risk of cancer was specifically associated with exposure to leather dust and solvents.

\section{Materials and methods}

Two cohorts of shoe manufacturing workers were included in the analysis. The first was a cohort of 5029 male shoe and boot manufacturing workers who were identified from the occupational information on the 1939 census records from three English towns (Rushden, Stafford, and Street) where the industry was an important employer. ${ }^{7}$ The previous report of this study was based on follow up from 1939 to 1982 . For the purpose of this analysis, the follow up period was extended to the end of 1991 and the cohort was restricted to the 4215 men known to be alive in 1950 because of concerns on the quality of mortality records for earlier years and for comparability with the second cohort. The second cohort consisted of 2008 workers (1005 men and 1003 women) who had ever been employed after 1939 at a large shoe manufacturing plant in Florence, Italy and who had worked between 1950 and $1984 .^{6}$ The previous report of this study was based on follow up from 1950 to 1984 . For the purpose of this analysis, the follow up period was extended to the end of 1990 .

A total of 6223 workers were included in 
Table 1 Characteristics of cohorts included in the study

\begin{tabular}{lcc}
\hline Characteristic & Florence cohort & English cohort \\
\hline Workers (n) & 2008 & 4215 \\
Deaths (n) & 333 & 3314 \\
Person-years at risk & 54395 & 103726 \\
Mean (SD) age at entry & $29(11)$ & $50(15)$ \\
Mean (SD) age at exit & $56(13)$ & $75(10)$ \\
Lost to follow/up (\%) & $92(4 \cdot 6)$ & $43(1 \cdot 0)$ \\
\hline
\end{tabular}

the analysis, contributing 158121 personyears at risk. Table 1 shows the mean age at entry and exit and other descriptive information for the cohorts. In the Florence cohort, $59.5 \%$ of the workers were employed for five or more years, $81.7 \%$ experienced more than 20 years since first exposure, and $34.4 \%$ were first employed at or before the age of 25 . The Florence cohort was substantially younger than the English cohort. The exposure information necessary to calculate time related variables was not available for the English shoe workers.

The work history information available for the two cohorts varied considerably. Multiple work histories, including the name of the job and start and end dates of each job during the time of employment at the plant being studied, were collected for all but 583 members of the Florence cohort. For members of the English cohort, only the job title as indicated on the 1939 census was collected, and dates of employment were not available. ${ }^{7}$ In the original study, job titles were classified into 14 groups by the Shoe and Allied Trades Research Association. Also, each worker was classified as to type of shoe manufacturing on the basis of the town of residence (men's boots, primarily welted (Rushden); women's and children's shoes (Street); and women's shoes (Stafford)).

For the purpose of this analysis an exposure classification scheme was developed on the basis of the work history information available for each cohort. A category of shoe production workers was created by excluding workers employed only in office or sales jobs or in trades or repair work not directly linked with shoe manufacture and including only those for whom work history information was available.

Table 2 Mortality from selected causes of death

\begin{tabular}{|c|c|c|c|c|c|c|}
\hline \multirow{3}{*}{$\frac{\text { Cause of death (ICD - 9) }}{\text { All causes (001-999) }}$} & \multicolumn{3}{|c|}{ English cohort } & \multicolumn{3}{|c|}{ Florence cohort } \\
\hline & \multirow{2}{*}{$\frac{O b s}{3314}$} & \multicolumn{2}{|c|}{$\operatorname{SMR}(95 \% C I)$} & \multirow{2}{*}{$\frac{O b s}{333}$} & \multicolumn{2}{|c|}{$S M R(95 \% C I)$} \\
\hline & & 81 & $(78-84)$ & & 87 & $(78-97)$ \\
\hline All malignant neoplasms $(140-208)$ & 646 & 75 & $(69-81)$ & 127 & 116 & $(96-138)$ \\
\hline Oesophagus (150) & 21 & 83 & $(51-127)$ & 0 & 0 & $(0-171)$ \\
\hline Stomach (15i) & 77 & 74 & $(58-92)$ & 25 & 186 & $(120-275)$ \\
\hline Colon (153) & 57 & 93 & $(70-120)$ & 10 & 165 & $(79-303)$ \\
\hline Rectum (154) & 51 & 109 & $(81-144)$ & 5 & 143 & $(47-334)$ \\
\hline Pancreas (157) & 25 & 70 & $(45-104)$ & 2 & 54 & $(7-195)$ \\
\hline Nose $(160)$ & 12 & 741 & $(383-1294)$ & 1 & 909 & $(23-5065)$ \\
\hline Larynx (161) & 6 & 66 & $(24-143)$ & 2 & 69 & $(8-250)$ \\
\hline Lung (162) & 186 & 60 & $(51-69)$ & 24 & 101 & $(65-150)$ \\
\hline Kidney (189) & 8 & 66 & $(28-129)$ & 4 & 222 & $(61-569)$ \\
\hline Bladder (188) & 34 & 84 & $(58-117)$ & 3 & 86 & $(18-251)$ \\
\hline Bone (170) & 6 & 208 & $(76-452)$ & 0 & 0 & $(0-345)$ \\
\hline Non-Hodgkin & 6 & 55 & $(20-120)$ & 2 & 106 & $(13-382)$ \\
\hline Leukaemias (20 & 16 & 89 & $(51-145)$ & 8 & 214 & $(92-421)$ \\
\hline Multiple mye & & 104 & $(45-206)$ & 3 & 288 & $(60-843)$ \\
\hline Nervous system (340-389) & 213 & 79 & $(69-90)$ & 2 & 19 & $(2-67)$ \\
\hline Circulatory system $(390-459)$ & 1608 & 85 & $(81-90)$ & 107 & 74 & $(61-90)$ \\
\hline Respiratory system $(460-519)$ & 468 & 72 & $(65-79)$ & 17 & 68 & $(40-109)$ \\
\hline Digestive system $(520-579)$ & 79 & 75 & $(59-93)$ & 9 & 30 & $(14-57)$ \\
\hline Genitourinary & 85 & 101 & $(81-125)$ & 4 & 62 & $(17-160)$ \\
\hline External causes (E800-E99 & 71 & 73 & $(57-92)$ & 13 & 49 & $(26-83)$ \\
\hline
\end{tabular}

This resulted in the exclusion of 320 members of the English cohort and 583 members of the Florence cohort. Although there are many potential exposures in the shoe manufacturing industry, leather dust and solvents are the most common and many workers in production areas might be expected to have at least some exposure. Exposure indices were developed for both of these substances.

Exposures to leather dust are highest during operations involving scouring, roughing, buffing, splitting, and skiving, but may also occur during cutting and trimming operations. ${ }^{1}$ Exposures may be higher and particle sizes smaller from operations with vegetable tanned or other sturdy leather, such as used for soles and boots, and can be very high when no dust controls are in place. Exposures were found to range from $7.5 \mathrm{mg} / \mathrm{m}^{3}$ during heel scouring operations to less than $0.5 \mathrm{mg} / \mathrm{m}^{3}$ during cutting operations in a survey in 1976 of a factory in the United Kingdom that produced welted footwear with leather uppers and soles. ${ }^{1}$ For the purpose of this analysis, workers were classified as probably exposed to leather dusts ( $n=1983$ in the English cohort, 209 in the Florence cohort) if they had worked in areas of the plants where leather finishing or cutting operations were performed. Workers were further classified as highly exposed to leather dusts ( $n=110$ and 46 ) if their job title indicated scouring, roughing, buffing, splitting, or skiving.

The primary source of exposure to solvent in the shoe manufacturing industry is glues which are used to attach parts of the shoe. Of the solvents used, benzene is of greatest concern with regard to cancer. Use of benzene began at the Florence shoe factory in the early 1950 s and it has been estimated that $70 \%$ of the glue by weight consisted of benzene before 1960. At the end of 1963, a national law limited benzene to $2 \%$ of total solvents in shoe glue. ${ }^{6}$ Exposure concentrations in the factory are not available, but exposures in the shoe industry in Pavia, Italy ranged from 25 to 600 ppm. ${ }^{1011}$ It is unclear how much exposure to benzene occurred among workers in the British shoe and boot industry. A wide variety of both aromatic and aliphatic solvents are found in the glues and cements used in the shoe industry, ${ }^{12}$ but documentation on the specific solvents to which the workers in this study were exposed are not available. Before the second world war, when all members of the British cohort were first employed, most shoe soles were primarily stitched to uppers and the volume of glue used was probably low compared with that experienced by the Italian cohort. ${ }^{1}$ For the purpose of this analysis, workers were classified as probably exposed to solvents $(n=1330$ in the English cohort, 651 in the Florence cohort) if they had worked in areas of the plants where assembly, preparation, fitting, lasting, and making operations were performed. Workers were further classified as highly exposed to solvents ( $n=106$ and 529) if their job title indicated gluing, glue preparation, or assembly.

Standardised mortality ratios (SMRs) were 
Table 3 Mortality from selected malignant neoplasms (ICD - 9) by exposure to leather dust and solvents

\begin{tabular}{|c|c|c|c|c|c|c|c|c|c|}
\hline \multirow[b]{2}{*}{ Exposure category } & \multicolumn{3}{|c|}{ Stomach cancer (151) } & \multicolumn{3}{|c|}{ Nasal cancer (160) } & \multicolumn{3}{|c|}{ Bone Cancer (170) } \\
\hline & Obs & $S M R$ & $(95 \% C I)$ & Obs & $S M R$ & $(95 \% C I)$ & Obs & $S M R$ & $(95 \% C I)$ \\
\hline English Cohort: & 74 & 77 & $(60-97)$ & 12 & 805 & $(416-1410)$ & 6 & 226 & $(83-491)$ \\
\hline Probable leather dust & 36 & 72 & $(51-100)$ & 9 & 1170 & $(534-2220)$ & 3 & 217 & $(45-635)$ \\
\hline High leather dust & 1 & 34 & $(1-190)$ & 1 & 2500 & $(63-13900)$ & 0 & 0 & $(0-4611)$ \\
\hline Probable solvent & 29 & 88 & $(59-127)$ & 2 & 385 & $(47-1390)$ & 1 & 112 & $(3-626)$ \\
\hline High solvent & 5 & 172 & $(56-402)$ & 0 & 0 & $(0-9220)$ & 0 & 0 & $(0-4611)$ \\
\hline Florence cohort: & 18 & 169 & $(100-267)$ & 1 & 1250 & $(31-6970)$ & 0 & 0 & $(0-444)$ \\
\hline Probable leather dust & 1 & 79 & $(2-442)$ & 0 & 0 & $(0->99999)$ & 0 & 0 & $(0-3354)$ \\
\hline High leather dust & 0 & 0 & $(0-1845)$ & 0 & 0 & $(0->99999)$ & 0 & 0 & $(0->99999)$ \\
\hline Probable solvent & 13 & 192 & $(102-329)$ & 1 & 2000 & $(50->99999)$ & 0 & 0 & $(0-753)$ \\
\hline High solvent & 12 & 193 & $(100-336)$ & 1 & 2000 & $(50->99999)$ & 0 & 0 & $(0-838)$ \\
\hline
\end{tabular}

calculated separately for each cohort from the person-years programme. ${ }^{13}$ Sex, age, and five year calendar period specific mortalities for Italy and for England and Wales were obtained from the World Health Organisation mortality databank and were used as reference rates. The $95 \%$ confidence intervals $(95 \% \mathrm{CI})$ were calculated on the assumption of a Poisson distribution for the observed deaths. ${ }^{14}$ Analyses were performed for all workers in the cohort and for production workers only, as well as according to leather dust and solvents exposure. Additional analyses were performed for the English cohort by town and type of shoe manufacturing and by the department categories originally developed for the study. Sex specific SMRs were calculated for members of the Florence cohort, but are only presented when the results were substantially different between sexes.

\section{Results}

A total of 3314 deaths occurrd in the English cohort and 333 deaths in the Florence cohort (table 2). Overall mortalities were significantly lower than expected in both national cohorts. Mortality due to diseases of the nervous system, the circulatory system, the respiratory system, and the digestive system were also lower than the general population in both cohorts. The English cohort experienced a deficit in total cancer mortality, but within the Florence cohort the risk of death due to cancer was higher than expected among men (SMR 130, 95\% CI 105-159), but not among women (SMR 88, 95\% CI 60-126).

The SMR for nasal cancer was significantly increased among all workers in both cohorts (only one case occurred, however, in the Florence cohort). No other cancer excess occurred consistently in both cohorts. Stomach, colon, and kidney cancer, as well as leukaemia and multiple myeloma were in excess in the Florence cohort, but only bone cancer and nasal cancer were in excess in the English cohort.

Table 3 shows mortality for selected cancer sites according to exposure categories of workers directly involved in shoe production. All 13 deaths from nasal cancer in the two cohorts occurred among the shoe production workers. The risk seemed to be associated with the level of exposure to leather dust, although only a single case (from England) occurred among workers in the highest exposure category.
Workers with probable exposure to solvents also seemed to have an increased risk. Most of the English cases occurred among workers employed in the manufacture of welted boots (observed (Obs) 10, SMR 926, 95\% CI 444-1700). However, excesses were also found among English workers who had been employed in the production of women's shoes (SMR 333, 95\% CI 8-1860) and women's and children's shoes (SMR 417, 95\% CI 10-2320), based on a single case each. No other notable excess of respiratory cancers nor a trend was found to be related to exposure to leather dust or solvents.

Excesses, based on small numbers, were found among production workers in the highest solvent exposure category for multiple myeloma, and non-Hodgkin's lymphomas in the Florence cohort (table 3). The highest risks of leukaemia, and four out of seven cases in the Florence cohort, were found among workers with the highest solvent exposure (SMR 280, 95\% CI 76-716); all these cases were men (SMR 345, 95\% CI 94-883), and three were first employed between 1950 and 1959 , when exposure to benzene was substantial (SMR 536, 95\% CI 111-1566). In the English cohort, no association between multiple myeloma and exposure to solvent was found, although workers employed in the manufacture of women's shoes had a excess risk of leukaemia (SMR 245, 95\% CI 106-482) and the risk was highest among workers in the lasting and making department (SMR 484, 95\% CI 100-1414). With the possible exception of multiple myeloma, no association between mortality from lymphatic and haematopoietic neoplasms and exposure to leather dust was found.

Excesses among production workers in the highest solvent exposure category were found for stomach and kidney cancer, although kidney cancer was present only in the Florence cohort (table 3). No consistent patterns of risk were found between stomach and kidney cancer and exposure to leather dust. The other cancer sites at increased risk in at least one cohort in the overall analysis (table 2) did not show a consistent pattern with exposure to either leather dust or solvent (detailed data not shown).

\section{Discussion}

The main strengths of this study are the increased statistical power to examine the risk 
Table 3 continued

\begin{tabular}{|c|c|c|c|c|c|c|c|c|c|c|c|}
\hline \multicolumn{3}{|c|}{ Kidney cancer (189) } & \multicolumn{3}{|c|}{ Non-Hodgkin's lymphoma $(200,202)$} & \multicolumn{3}{|c|}{ Multiple myeloma (203) } & \multicolumn{3}{|c|}{ Leukaemia (204-208) } \\
\hline Obs & $S M R$ & $(95 \% C I)$ & Obs & $S M R$ & $(95 \% C I)$ & Obs & SMR & $(95 \% C I)$ & Obs & $S M R$ & $(95 \% C I)$ \\
\hline $\begin{array}{l}8 \\
5 \\
1 \\
1 \\
0 \\
3 \\
0 \\
0 \\
3 \\
3\end{array}$ & $\begin{array}{r}71 \\
87 \\
313 \\
25 \\
0 \\
216 \\
0 \\
0 \\
353 \\
400\end{array}$ & $\begin{array}{l}(31-141) \\
(28-204) \\
(8-1741) \\
(1-137) \\
(0-1190) \\
(45-631) \\
(0-1845) \\
(0-9223) \\
(73-1031) \\
(83-1169)\end{array}$ & $\begin{array}{l}3 \\
1 \\
0 \\
2 \\
0 \\
2 \\
0 \\
0 \\
2 \\
2\end{array}$ & $\begin{array}{r}30 \\
20 \\
0 \\
54 \\
0 \\
138 \\
0 \\
0 \\
244 \\
274\end{array}$ & $\begin{array}{l}(6-88) \\
(0-110) \\
(0-1320) \\
(7-196) \\
(0-1370) \\
(17-498) \\
(0-1850) \\
(0-9220) \\
(30-881) \\
(33-990)\end{array}$ & $\begin{array}{l}7 \\
4 \\
1 \\
3 \\
1 \\
3 \\
1 \\
0 \\
1 \\
1\end{array}$ & $\begin{array}{r}99 \\
112 \\
476 \\
115 \\
526 \\
370 \\
909 \\
0 \\
217 \\
244\end{array}$ & $\begin{array}{l}(40-205) \\
(30-286) \\
(12-2650) \\
(24-336) \\
(13-2930) \\
(76-1080) \\
(23-5070) \\
(0->99999) \\
(5-1210) \\
(6-1360)\end{array}$ & $\begin{array}{r}14 \\
7 \\
0 \\
4 \\
0 \\
7 \\
0 \\
0 \\
4 \\
4\end{array}$ & $\begin{array}{r}85 \\
83 \\
0 \\
68 \\
0 \\
244 \\
0 \\
0 \\
252 \\
280\end{array}$ & $\begin{array}{l}(47-143) \\
(33-171) \\
(0-753) \\
(19-175) \\
(0-785) \\
(98-503) \\
(0-946) \\
(0-6150) \\
(69-644) \\
(76-716)\end{array}$ \\
\hline
\end{tabular}

associated with rare cancers and the ability to detect excess risks that may be associated with long latency periods, achieved by extending the follow up period of two studies, and the ability to examine the risks associated with exposure to leather dusts and solvents achieved by a common exposure assessment. It is interesting to note that, despite the long follow up, the healthy worker effect is still evident in both studies, as reflected by the decreased risks found for deaths due to all causes and diseases of circulatory, respiratory, digestive, and nervous systems.

The main limitations of this study are the lack of detailed exposure information available and the differences in the information available from the two cohorts. In particular, this study lacked information on exposure to specific chemicals within the shoe industry and information on duration of exposure was not present for the English cohort. Also, the exposures among the English cohort occurred long ago and may have differed from those of the Florence cohort. Although some information on the exposures among the Florence workers was available, there was little information on actual working conditions within the English factories. However, given that the exposure information was recorded and classified without knowledge of disease status, the misclassification that occurred is likely to have been non-differential and the effect would be to mask or attenuate exposure disease relations. The differences in exposure and the different time period of employment of the two cohorts may explain some of the differences in cancer site specific risks found between the two studies. Furthermore, the number of deaths in the older (English) cohort tends to overwhelm the results of the Florence cohort. One additional limitation of this study is the use of national reference rates, which may not reflect local differences in disease mortality in the two countries. However, for the types of neoplasms of primary interest, regional variation in Italy and England and Wales has not been shown to be important, at least in recent years. ${ }^{15}$

A large excess risk of nasal cancer was found in these analyses which seemed to be associated with exposure to leather dusts. An excess was found among both the English and Florence shoe workers, although in the Italian study it was based on a single case (with about $0 \cdot 1$ expected cases). In the English cohort, most cases were among the workers employed in the manufacture of welted boots, a sector of the industry thought to have had the highest exposure to leather dust. Many case-control studies have found a relation between exposure to leather dust or work in this industry and nasal cancer, ${ }^{16-19}$ but the results of cohort studies have been less consistent. Although the previous report of the English shoe workers reported an excess of nasal cancer, ${ }^{7}$ other studies have either found no cases $^{38920}$ or not reported their results for this site. ${ }^{6}$ The mechanism by which exposure to leather dust may increase the risk of nasal cancer is not known.

This study also found evidence for an association between exposure to solvents among shoe workers and the risk of leukaemia, and possibly other lymphatic and haematopoietic neoplasms. The excess among workers with the highest likelihood of solvent exposure was present only in the Florence study. The highest risk among the Florence shoe workers was among male workers first employed in the $1950 \mathrm{~s}$, the time period when benzene was introduced into the industry and exposures were likely to have been high. Also, it is possible that cumulative exposure to benzene was higher among men than among women. Among the English shoe workers, the only increased risk was among workers who produced women's shoes, particularly those in the lasting and making department who were likely to have been exposed to solvents. However, it is not known whether benzene was a component of the glues used by the English workers. The association between leukaemia and exposure to benzene is well established $^{21}$ and an increased risk of leukaemia has been found among other groups of shoe workers exposed to benzene in Italy and Turkey. ${ }^{1022}$ Based on these findings, exposure to benzene in glues is likely to be the cause of the excess of leukaemia in the shoe manufacturing industry.

An increased risk of stomach, bladder, and kidney cancer was found in workers with the highest exposure to solvents. With the exception or stomach cancer, all the associations were based on small numbers. The association between stomach and bladder cancer and workers with the highest exposure to solvents was found in both cohorts, although the excess of kidney cancer was only present among Florence workers. It is important to note that in the province of Florence mortalities from stomach cancer are higher than in the country as a whole: during $1976-80$ they were $41 \cdot 1 / 100000$ in men and $20 \cdot 7 / 100000$ in 
women, compared with $24 \cdot 5 / 100000$ and $12 \cdot 0 / 100000$ in Italy. ${ }^{12}$ Excesses of digestive and urinary tract cancers, such as bladder, ${ }^{45}$ kidney, ${ }^{48}$ stomach, ${ }^{915}$ and rectum, ${ }^{39}$ have been found in other studies of shoe workers but have not been consistently reported and have not been linked with particular exposures within the industry.

This study did not find any evidence for an increased risk of lung cancer, and a significant deficit of this cancer was found in the English cohort. It has been reported that smoking was not permitted in the work area of the English shoe factories ${ }^{7}$ and this may, at least in part, account for this deficit.

In summary, the findings of this study confirm findings of previous studies that there are associations between exposure to leather dust and nasal cancer and between exposure to benzene and leukaemia in the shoe manufacturing industry. Some evidence for an excess risk of stomach, bladder, and kidney cancer as well as multiple myeloma and non-Hodgkin's lymphoma was found among workers employed in jobs with the highest exposure to solvent. These findings, however, were based on small numbers and, with the exception of stomach and bladder cancer, were found only in the Florence cohort; they therefore need confirmation from future studies.

This work was partially funded by the European Commission Directorate-General V (contract No 91 CVVE2015-0) and by the European Commission BIOMED-1 programme (contract No BMH1- CT92-1110). FH and PD were supported by research training fellowships awarded by the International Agency for Research on Cancer. E Matos, $H$ Vainio, and G Ferro contributed to early phases of this project.

1 International Agency for Research on Cancer. Boot and sho manufacture and repair. LARC monographs on the evaluation of the carcinogenic risk of chemicals to humans, vol 25 woods, leather and some associated industries. Lyon: IARC 1981:249-77.

2 International Agency for Research on Cancer. Boot and shoe manufacture and repair. LARC monographs on the evaluation of the carcinogenic risk of chemicals to humans, suppl 7 overall evaluations of carcinogenicity: an updating of IARC overall evaluations of carcinogenicity: an updating of IAR
monographs volumes 1-42. Lyon: IARC, 1987:232-5.
3 DeCoufle $P$, Walrath J. Proportionate mortality among US shoeworkers, 1966-77. Am $\mathfrak{f}$ Ind Med 1983;4:523-32.

4 Malker HK, Malker BK, McLaughlin JK, Blot WJ. Kidney cancer among leather workers. Lancet 1984;i:56

5 Morrison AS, Ahlbom A, Verhoek WG, Aoli K, Leck I Ohno $\mathrm{Y}$, et al. Occupational and bladder cancer in Boston, USA, Manchester, UK, and Nagoya. Fapan Fournal of Epidemiology and Community Health 1985;39. 294-300.

6 Paci E, Buiatti E, Seniori-Costantini A, Miligi L, Pucci N, Scarpelli A, et al. Aplastic anaemia, leukaemia and other Scarpelli $A, e t$ al. Aplastic anaemia, leukaemia and other benzene. Scand $₹$ Work Environ Health 1989;15:313-8.

7 Pippard EC, Acheson ED. The mortality of boot and shoe makers, with special reference to cancer. Scand $\mathcal{f}$ Work Environ Health 1985;11:249-55.

8 Walker J, Bloom T, Stern F, Okun A, Fingerhut $M$ Halperin W. Mortality of workers employed in shoe man ufacturing. Scand $¥$ Work Environ Health 1993;19:89-95.

9 Walrath J, Decoufle P, Thomas TL. Mortality amon workers in a shoe manufacturing company. Am $\mathcal{f}$ Ind Med 1987;12:615-23.

10 Vigliani EC. Leukemia associated with benzene exposure. Ann NY Acad Sci 1976;271:143-51.

11 Vigliani EC, Forni A Benzene and leukemia. Environ Res 1976;11:122-7.

12 Scarpelli A, Miligi L, Seniori Costantini A, Alberghini Maltoni S. Exposure to solvents in the shoe and leather goods industries. Int $\mathcal{F}$ Epidemiol 1993;22:S46-9.

13 Coleman M, Douglas A, Hermon C, Peto J. Cohort study analysis with a FORTRAN computer program. Int Epidemiol 1986;15:134-7.

14 Breslow NE, Day NE. Statistical methods in cancer research, volume ii-the design and analysis of cohort studies. Lyon: IARC, 1987: 65-72. (IARC Sci Publ No 82.)

15 Smans M, Muir CS, Boyle P. Atlas of the cancer mortality in the European economic community. Lyon: IARC, 1992. the European economic com
(IARC Sci Publ No 107.)

16 Luce D, Gerin M, Leclerc A, Morcet JF, Brugere J, Goldberg $M$. Sinonasal cancer and occupational exposure to formaldehyde and other substances. Int $\mathcal{F}$ Cancer 1993;53:224-31.

17 Magnani C, Comba P, Ferraris F, Ivaldi C, Meneghin M Terracini B. A case-control study of carcinomas of the nose and paranasal sinuses in the woollen textile manufacturing industry. Arch Environ Health 1993;48:94-7.

18 Comba P, Battista G, Belli S, de-Capus B, Merler E, Orsi D, et al. A case-control study of cancer of the nose and paranasal sinuses and occupational exposures. Am f Ind Med 1992;22:511-20.

19 Merler E, Baldasseroni A, Laria R, Faravelli P, Agostini R, Pisa $R$, et al. On the causal association between exposure Pisa $R$, et al. On the causal association between exposure to leather dust and nasal cancer: further evidence

20 Garabrant GH, Wegman DH. Cancer mortality among shoe and leather workers in Massachusetts. Am $\mathcal{F}$ Ind Med 1984;5:303-14.

21 International Agency for Research on Cancer. Benzene. LARC monographs on the evaluation of the carcinogenic risk of chemicals to humans, vol 29. some industrial chemical and dyestuffs. Lyon: IARC, 1982:93-148.

22 Aksoy M, Dincol K, Erdem S, Dincol G. Acute leukaemi due to chronic exposure to benzene. Am $f$ Med 1972;18: 387-94. 